\title{
Sensitivity Analysis of Coastal City Tourism and Environmental Systems Based on Coupling Model
}

\author{
Shengkui Duan, ${ }^{1,2}$ Li Zhang, ${ }^{3}$ and Wei-Ling $\mathrm{Hsu}^{4 *}$ \\ ${ }^{1}$ College of Geography and Tourism, Anhui Normal University, \\ No. 189, South Jiuhua Rd., Wuhu City, Anhui 241002, China \\ ${ }^{2}$ School of History, Culture and Tourism, Huaiyin Normal University, \\ No. 111, Changjiang West Rd., Huai'an City, Jiangsu 223300, China \\ ${ }^{3}$ Hotel School, Jiangsu Food and Pharmaceutical Science College, \\ No. 4, Meicheng Rd., Huai'an City, Jiangsu 223003, China \\ ${ }^{4}$ School of Urban and Environmental Science, Huaiyin Normal University, \\ No. 111, Changjiang West Rd., Huai'an City, Jiangsu 223300, China
}

(Received November 25, 2019; accepted April 16, 2020)

Keywords: coastal city, tourism industry, ecological environment, sensitivity, coupling, information entropy

The tourism industry and ecological environment are two major material systems that are mutually inductive and restrictive. For the sustainable development of coastal cities, a correct understanding of the sensitive relationship between the two systems is of great significance. The present study took the coastal city of Sanya in China as an example, and data from the period 2008-2017 was used to construct a tourism industry-ecological environment coupling coordination degree model (CCDM) of Sanya. The results showed that the coupling coordination degree exhibited an increasing trend over time, improving from minimal coordination to favorable coordination; furthermore, the economic efficiency and environmental protection subsystems made the greatest contributions to the tourism-environment coupling system. In addition, the results demonstrated that the combination of the CCDM and information entropy weight (IEW) is an effective approach to evaluating the sensitivity between systems.

\section{Introduction}

Following continual improvements in productivity levels and the increased importance attached to leisure, the global tourism industry has undergone rapid development. According to estimates by the World Travel and Tourism Council, the contribution of world tourism to global GDP in 2016 was US\$8.2 trillion, accounting for 11\% of global GDP. China has benefited from the policies of Chinese economic reform and rapid growth in a stable economic environment, which have accelerated the development of the country's tourism industry. In 2017, the number of Chinese domestic tourists reached 5000 million and they generated an income of $\$ 6548.22$ billion, making tourism one of the pillars of China's national economic development. However, 
the development of tourism in many regions is at the expense of the ecological environment; that is, the arrival of tourists affects the natural cycle of ecosystems. In particular, some ecologically fragile areas, such as coastal areas, are sensitive to environmental factors and have poor ecological stability; furthermore, the natural environment there is prone to develop in directions unfavorable to people when subjected to interference. In this study, a coupling model was adopted to conduct an objective evaluation of the sensitivity of a coastal city's ecological system to tourism activities, which was expected to provide a basis for decision-making related to the rational development of tourism resources, the planning of tourism activities, and the reduction of negative effects from tourism. ${ }^{(1,2)}$ Sanya is located at the southernmost tip of Hainan Island in China and is between $18^{\circ} 09^{\prime} 34^{\prime \prime}$ and $18^{\circ} 37^{\prime} 27^{\prime \prime}$ north and $108^{\circ} 56^{\prime} 30^{\prime \prime}$ and $109^{\circ} 48^{\prime} 28^{\prime \prime}$ east (Fig. 1). It is one of China's famous tropical coastal cities with a coastline measuring $209.1 \mathrm{~km}$ and has 19 harbors, 40 outlying islands, and rich natural resources. In 2017, Sanya's total tourism revenue reached $\$ 58.20$ billion, accounting for $76.74 \%$ of the city's GDP, indicating that tourism is one of its leading industries. Rational planning and strict management have been lacking since the development of tourism in Sanya, with hotels clustered at the seaside, polluting the marine environment and destroying the natural landscape. The problem of tourist overload on its beaches has resulted in a declining recreation quality as well as the haphazard disposal of solid waste. Despite the development of tourism in Sanya being dependent on the support of the ecological environment, it is also damaging the ecological environment. Therefore, it is of practical significance to deal with the relationship between tourism activities and environmental protection for the sustainable development of Sanya. In the present study, the coupling coordination degree model (CCDM) was used for a comprehensive assessment of the sensitive relationship between Sanya's tourism industry and ecological environmental systems to provide a theoretical basis for the sustainable development of coastal city tourism in China.

The rest of the paper is organized as follows. Section 2 extensively reviews the latest relevant literature. Section 3 describes the coupling research method and establishes the system for evaluating the coordination between the development of the tourism industry and the ecological environment in Sanya. Section 4 analyzes the evolution characteristics of the

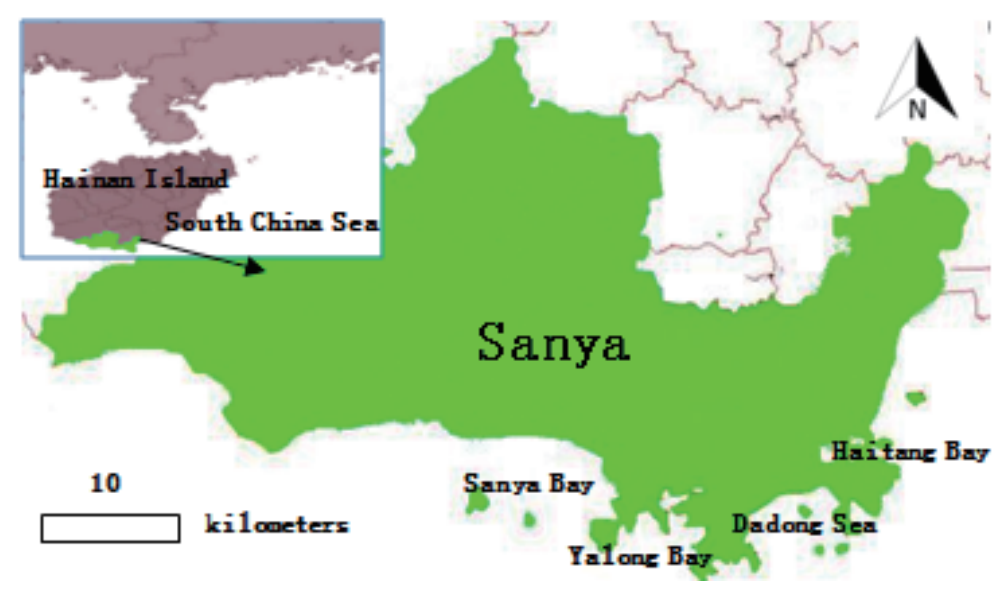

Fig. 1. (Color online) Location of costal city of Sanya. 
coupling coordination between the tourism industry and the ecological environment in Sanya from 2008 to 2017. Finally, Sect. 5 summarizes the results of this study and recommends future research directions.

\section{Literature Review}

The ecological environment is a solid foundation for the development of the tourism industry, and furthermore, the tourism industry is strongly dependent on the ecological environment. The process of tourism development should be people-oriented and should adhere to the concept of low-carbon tourism, strengthen the protection of the ecological environment, reduce the effects of visitors on the environment, and promote the coordinated development of the tourism industry and ecological environment. Studying the relationship between the tourism industry and the ecological environment is conducive to promoting the sustainable development of the tourism industry. Foreign scholars such as Mbaiwa studied the negative impact of tourism development on the ecological environment. ${ }^{(3)}$ Dubois et al. found that the development of tourism has had adverse effects on the atmospheric environment, which should be paid attention to. ${ }^{(4)}$ Gössling ${ }^{(5)}$ and Anisimov and Ryzhenkov ${ }^{(6)}$ believed that laws and regulations should be further improved, and policies for tourism development and environmental protection should be introduced to promote the development of the tourism industry. Holden noted that the development of tourism is closely related to the natural environment and concluded that establishing a strong environmental protection ethics system is necessary to meet the environmental challenges facing the tourism industry's development. ${ }^{(7)}$ Furthermore, foreign scholars have established correlation models between the tourism industry and the ecological environment. For example, Lacitignola et al. established a socio-ecological relationship model based on tourism, ${ }^{(8)}$ Patterson et al. constructed a comprehensive dynamic model for the relationship between the tourism development and the environment, ${ }^{(9)}$ and Wei et al. established a mathematical survival theory on the relationship between the tourism development and the environment. ${ }^{(10)}$ Additionally, domestic scholars have conducted studies on the coordinated development and development trends of China's tourism economy and ecological environment, concluding that the two are strongly correlated. In physics, Yang first introduced the concept of the coupling degree in a study of the relationship between the urban environment and the economic development. ${ }^{(11)}$ Liao cited the coupling coordination degree for its further development. ${ }^{(12)} \mathrm{Fu}$ et al. used the coupling coordination and obstacle model to analyze the tourism-environment coupling coordination relationship in Guizhou from 2008 to 2016. ${ }^{(13)}$ Hu et al. used the coupling coordination model to reveal that the tourism-environment coordination degree has continuously improved in Changsha from minimal coordination to favorable coordination. ${ }^{(14)}$ At present, domestic scholars' research on such studies has been limited to inland cities and has not focused on coastal cities. Coastal cities are unique microregions, and developing their tourism industry has become a crucial approach in their economic development. Moreover, the development of the tourism industry in coastal cities is highly dependent on the ecological environment. Accordingly, Sanya on Hainan Islandthe second largest island of China-was employed as an example in this study, and quantitative 
analysis was performed to construct a coupling development index system for the tourism industry and ecological environment there; furthermore, the information entropy weight (IEW) was used to obtain weights objectively. The aim of this study was to explore the dynamic trend of the coupled development of the tourism industry and ecological environment in coastal cities, identify the indicators that contribute to the subsystems, improve the theoretical system of tourism industry and ecological environment research in coastal cities, and promote the sustainable development of coastal cities in China.

\section{Research Method}

\subsection{Conclusion of evaluation index system}

The design of the evaluation index system is the basis for studying the coupling coordination of regional tourism industries and tourism environments. A requirement during index selection is to pay attention to the representativeness and scientific nature of the indices as well as the logical relationship between them while simultaneously reflecting the interactions and relationships between the various systems. Under the guidance of the aforementioned principles, we first compiled the relevant literature on the tourism industry and tourism environment according to the evaluation method of the coupling system. The compiled literature was then combined with the opinions of experts and scholars in related fields to select the indices with greatest use by researchers in recent years. Subsequently, the indices were divided into those for two systems: the tourism industry and ecological environment systems. The tourism industry system consisted of two subsystems - development scale and economic benefit - and the environmental system was divided into three subsystems - ecological quality, environmental protection, and environmental pollution. Table 1 presents the indices. To eliminate human interference in the calculation of index weights, IEW was used to select the weight of each index to yield more objective evaluation results. The original data were from the Hainan Statistical Yearbook, Statistical Communique of Sanya on National Economic and Social Development, and Communique of Sanya on the Environmental Status between 2008 and 2017.

\subsection{Evaluation method}

\subsubsection{Development index evaluation using subsystems}

IEW was used to determine the weights and the original data were standardized to reduce deviation due to subjective factors. Moreover, to increase the comparability and better reflect regional-level differences, the national average was used as a reference for comparative analysis. The main steps were as follows:

1. Data standardization

Because of the different dimensions of each index in the index system, each index value was standardized for a comprehensive evaluation. We assumed that the $j$ th index value of the $i$ th 
Table 1

Evaluation system and weight of coordination development of tourism industry and ecological environment in Sanya.

\begin{tabular}{|c|c|c|c|c|}
\hline Subsystem & First-class index & Second-class index & Direction & Weight \\
\hline \multirow{10}{*}{$\begin{array}{l}\text { Tourism } \\
\text { system }\end{array}$} & \multirow{5}{*}{$\begin{array}{l}\text { Scale of } \\
\text { tourism }\end{array}$} & Number of domestic tourists (10000 person-times) & + & 0.0978 \\
\hline & & Number of inbound tourists (10000 person-times) & + & 0.0978 \\
\hline & & Airport passenger flow (10000 person-times) & + & 0.0884 \\
\hline & & Number of tourist employees (10000 persons) & + & 0.0717 \\
\hline & & Occupancy rate of tourist hotel room (\%) & + & 0.0721 \\
\hline & \multirow{5}{*}{$\begin{array}{l}\text { Economic } \\
\text { benefits }\end{array}$} & Domestic tourism revenue (billion dollars) & + & 0.1104 \\
\hline & & Foreign exchange income of tourism (billion dollars) & + & 0.1498 \\
\hline & & Accommodation and catering turnover (billion dollars) & + & 0.0934 \\
\hline & & Contribution of tourism to GDP (\%) & + & 0.1235 \\
\hline & & Proportion of tourism income in tertiary industry (\%) & + & 0.0910 \\
\hline \multirow{10}{*}{$\begin{array}{l}\text { Environmental } \\
\text { system }\end{array}$} & \multirow{4}{*}{$\begin{array}{l}\text { Ecological } \\
\text { quality }\end{array}$} & Rate of excellent air quality (\%) & + & 0.0895 \\
\hline & & Forest coverage $(\%)$ & + & 0.0692 \\
\hline & & Green coverage rate of built-up area (\%) & + & 0.0634 \\
\hline & & Per capita park green space area $\left(\mathrm{m}^{2}\right)$ & + & 0.0731 \\
\hline & \multirow{3}{*}{$\begin{array}{l}\text { Environmental } \\
\text { pollution }\end{array}$} & Discharge of industrial wastewater (10000 tons) & - & 0.1456 \\
\hline & & Industrial exhaust emissions (billion $\mathrm{m}^{3}$ ) & - & 0.0881 \\
\hline & & Production of industrial solid waste (10000 tons) & - & 0.0869 \\
\hline & \multirow{3}{*}{$\begin{array}{l}\text { Environmental } \\
\text { protection }\end{array}$} & Centralized treatment rate of urban domestic sewage (\%) & + & 0.1245 \\
\hline & & Industrial wastewater treatment capacity (10000 tons) & + & 0.1397 \\
\hline & & Comprehensive utilization rate of industrial solid waste (\%) & + & 0.1198 \\
\hline
\end{tabular}

year was $x_{i j}$, and we set the maximum value of index $j$ as $x_{\max }$ and the minimum value as $x_{\min }$. The normalized value $x_{i j}^{\prime}$ was obtained according to the positive and negative attributes of the index [Eq. (1)].

$$
\text { Positive index } x_{i j}^{\prime}=\frac{x_{i j}-x_{\min }}{x_{\max }-x_{\min }} \text {, Negative index } x_{i j}^{\prime}=\frac{x_{\max }-x_{i j}}{x_{\max }-x_{\min }}
$$

Here, $i=1,2, \ldots, m$ indicates the year number and $j=1,2, \ldots, n$ indicates the index number. The same notation is applied in the following.

\section{Determination of the index weights}

On the basis of the process of calcurating IEW, the normalized index weight of index $j\left(s_{i j}\right)$ was first calculated [Eq. (2)], after which the entropy value of index $j\left(h_{j}\right)$ was calculated [Eq. (3)]. Finally, we calculated the difference coefficient of index $j\left(a_{j}\right)$ to determine its weight $\left(w_{j}\right)$ [Eqs. (4) and (5)].

$$
\begin{gathered}
s_{i j}=\frac{x_{i j}^{\prime}}{\sum_{i=1}^{m} x_{i j}^{\prime}} \\
h_{j}=-\frac{1}{\ln m} \sum_{i=1}^{m} s_{i j} \ln s_{i j}
\end{gathered}
$$




$$
\begin{gathered}
a_{j}=1-h_{j} \\
w_{j}=\frac{a_{j}}{\sum_{j=1}^{n} a_{j}}
\end{gathered}
$$

3. Development index calculation using subsystems

The development level index of a subsystem at a certain location in the $i$ th year $\left(u_{i}\right)$ was calculated as follows using the weighting method.

$$
u_{i}=\sum_{j=1}^{n} w_{j} x_{i j}^{\prime}
$$

\subsubsection{Coupling coordination degree evaluation}

The coupling degree is a crucial way of describing the mutual influence and coordination degree of a system. It originates from the capacity coupling coefficient model in physics and has gradually been applied in research fields such as biology, geography, economics, and tourism. Drawing on existing research results, we constructed the following CCDM $D$ that reflected the coordinated development of the tourism industry and tourism environment systems.

$$
\begin{gathered}
D\left(u_{1}, u_{2}\right)=\sqrt{C \times T} \\
C=\left(\frac{u_{1} \times u_{2}}{\left(\frac{u_{1}+u_{2}}{2}\right)}\right)^{\frac{1}{2}} \\
T=\alpha u_{1}+\beta u_{2}
\end{gathered}
$$

In the equation, $D$ denotes the coupling coordination degree, $C$ represents the coupling degree of the two systems, $T$ denotes the comprehensive coordination index of the two systems, $u_{1}$ and $u_{2}$ are the comprehensive evaluation indices of the tourism industry and ecological environment systems, respectively, and $\alpha$ and $\beta$ are undetermined coefficients. Considering that the two systems are of equal importance, $\alpha$ and $\beta$ are both taken as 0.5 in accordance with common practice.

\section{Results and Analysis}

\subsection{Coupling degree analysis}

The comprehensive development level of the tourism industry system has been gradually increasing (Fig. 2) from 2008 (0.1693) to 2017 (0.9535), a relatively substantial increase. The 


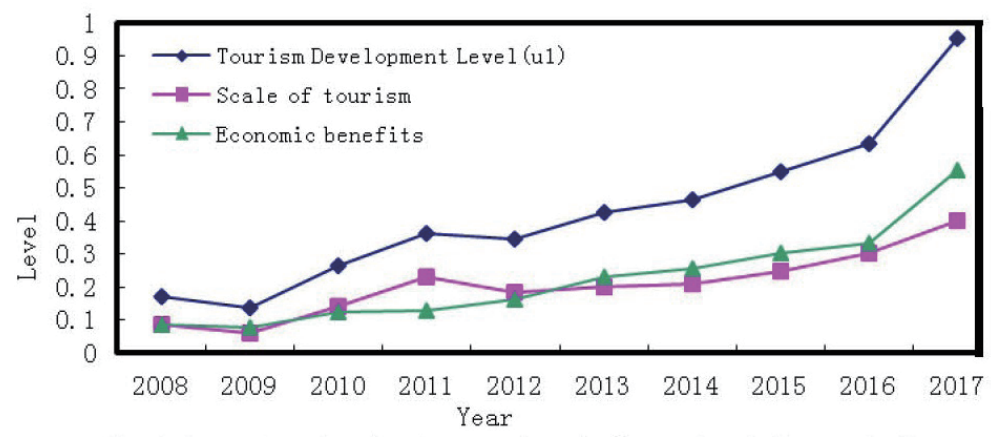

Fig. 2. (Color online) Comprehensive development level of tourism industry in Sanya.

development around 2008-2009 was slightly volatile because of the financial crisis and the Wenchuan earthquake of 2008, which affected both domestic and international tourism. Following the publication of "Several Opinions of the State Council on Promoting the Construction and Development of the Hainan International Tourism Island" on January 4, 2010, the tourism industry entered a rapid stage of development from 2010 to 2013. Economic benefits had the greatest weight (56.81\%), whereas the indices of foreign exchange earnings from tourism, tourism earnings as a proportion of GDP, and domestic tourism earnings had the greatest impact, reaching 38.4\%. In 2013, tourism development entered a leapfrogging stage, and since then economic efficiency has improved steadily and exceeded the scale of tourism development. This indicates that the tourism industry in Sanya has attained some success in terms of connotative development for the transformation and upgrading of its tourism industry. In general, economic efficiency has had the greatest impact on the comprehensive development level of the tourism industry system.

The comprehensive development level of the ecological environment system in Sanya has fluctuated greatly (Fig. 3), reaching the highest value (0.7465) in 2012, with environmental protection having the largest weight $(38.4 \%)$. The three indices of industrial wastewater discharge, industrial wastewater treatment, and centralized treatment rates of urban domestic sewage had the greatest impacts on the comprehensive level of the environmental system. However, the comprehensive development level of the ecological environmental system in Sanya increased from 2008 to 2012 but began to decline from 2012 because of issues such as environmental pollution and protection. Among the indices, environmental quality and environmental protection have exhibited relatively stable development and were both rising prior to 2013, after which they slightly decreased. However, the decline in environmental pollution was greater, dropping from its highest value of 0.2855 in 2010 to 0.1175 in 2017.

From the perspective of the coupled development trend of the tourism industry and ecological environment systems (Fig. 4), the comprehensive evaluation index of the ecological environment system before 2014 was higher than that of the tourism industry system, indicating that the tourism industry lagged behind the ecological environment in terms of development in 2008-2014, that is, $u_{1}<u_{2}$. After 2015, the comprehensive evaluation index of the tourism industry system was significantly higher than that of the ecological environment system, that is, $u_{1}>u_{2}$. This indicates that the tourism industry in Sanya has been developing 


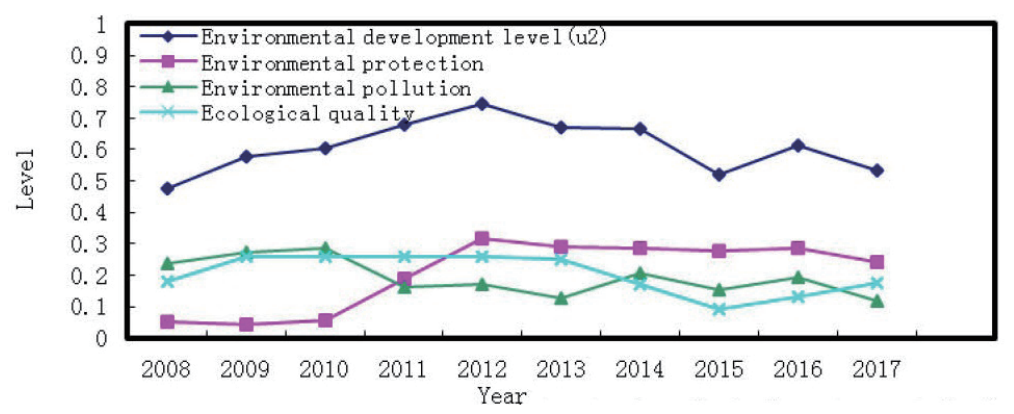

Fig. 3. (Color online) Comprehensive development level of ecological environment in Sanya.

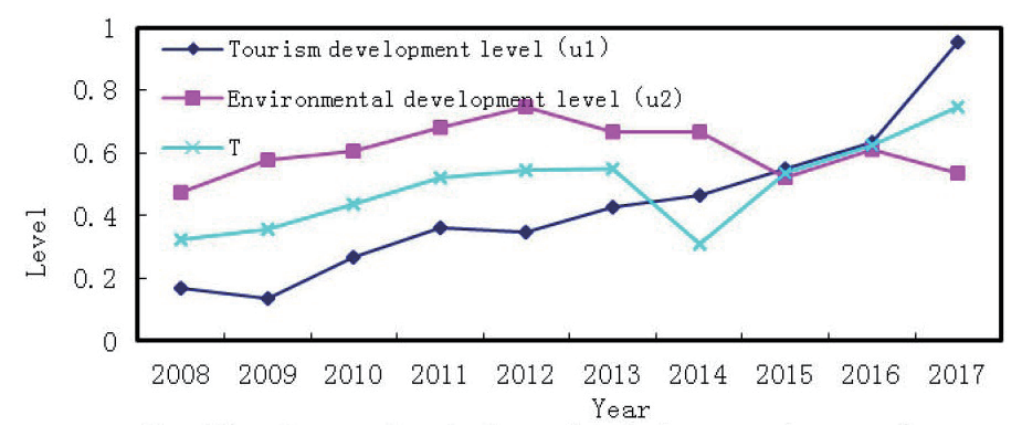

Fig. 4. (Color online) Development level of tourism industry and ecological environment in Sanya.

faster than ecological environment protection, resulting in an expanding gap between the two. Accordingly, the ecological environment has become a critical factor restricting the development of the tourism industry.

\subsection{Coupling coordination degree analysis}

In this study, the widely used classification standard of the 10-point evaluation level from the coupling coordination degree - first proposed by Liao ${ }^{(12)}$ — was adopted. A value of 0.5 is generally regarded as the threshold of whether coordination exists, with a lower value indicating a lower coordination level (Table 2). According to the coupling coordination degree score, the tourism-environment system of Sanya from 2008 to 2017 can be divided into three stages (Fig. 5).

The first stage (2008-2009) was a minimal coordination stage, during which the coupling coordination development of the tourism and environmental systems was relatively stable and at a low level (0.5323 in 2008 and 0.5297 in 2009). The level of tourism development at this stage was low, and the construction and protection of the ecological environment were slowing.

The second stage (2010-2014), with intermediate coordination, exhibited a clear upward development trend and high-level development. The coupling coordination degree index increased from 0.5297 in 2009 to 0.6332 in 2010 and reached 0.7463 in 2014 . Following the rapid development of the tourism industry, environmental protection and ecological quality also developed quickly. The interactive effect of the tourism industry and ecological environment 
Table 2

Coupling coordination levels.

\begin{tabular}{lcccc}
\hline $\begin{array}{l}\text { Coupling coordination } \\
\text { degree }(D)\end{array}$ & Coordination level & & $\begin{array}{l}\text { Coupling coordination } \\
\text { degree }(D)\end{array}$ & Coordination level \\
\cline { 1 - 2 } 0.09 & Extreme disorder & & $0.50-0.59$ & Minimal coordination \\
$0.10-0.19$ & Serious disorder & & $0.60-0.69$ & Primary coordination \\
$0.20-0.29$ & Moderate disorder & & $0.70-0.79$ & Intermediate coordination \\
$0.30-0.39$ & Slight disorder & & $0.80-0.89$ & Favorable coordination \\
$0.40-0.49$ & On the verge of disorder & $0.90-1$ & Strong coordination \\
\hline
\end{tabular}

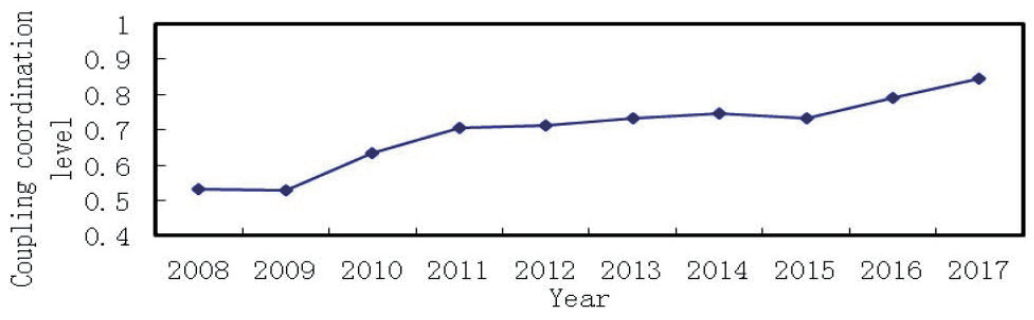

Fig. 5. Coupling coordination level of tourism industry and ecological environment in Sanya.

in Sanya began to show, and the level of tourism development gradually approached that of environmental development.

The third stage (2015-2017) exhibited a slow rise in coupling coordination development, which improved from intermediate coordination to favorable coordination, reaching 0.8454 in 2017. The number of tourists in 2017 was 18.3097 million, and the comprehensive income from tourism was $\$ 58.20$ billion. The level of development of the tourism industry surpassed that of environmental development. Despite the tourism industry demonstrating an obvious driving effect, environmental development was lagging behind, thereby affecting the future development of the tourism industry.

\section{Discussion}

The coupling coordination degree of the tourism industry and ecosystem in Sanya has been rapidly improved, with the coordination degree index increasing from 0.5323 in 2008 to 0.8454 in 2015, indicating speedy development. Thereafter, the coupling coordination of the tourism industry and ecological environment in Sanya gradually improved, entering a stage of intermediate coordination in 2010. In 2016, Sanya reached the high coordination stage, and its coordination degree displayed a more favorable trend. The comprehensive evaluation indices of the tourism industry and ecological environment systems in Sanya exhibited staged development, with the indices of the tourism industry being lower than those of the ecological environment before 2014. In addition, the efforts toward the protection and construction of the ecological environment system were superior to the development speed of the tourism industry system; that is, the ecological environment promoted the development of the tourism industry. 
After 2014, the development speed of the tourism industry system surpassed the efforts toward the protection and construction of the ecological environment system, and furthermore, the ecological environment became a factor constraining tourism development. The relatively objective and credible results of this study help to identify the complex interactions between the tourism and environmental systems. This, in turn, will help achieve sustainable development strategies while more favorably balancing the relationship between the growth of the tourism industry and environmental protection.

Because of the rapid development of the society and economy, the improvement of people's living standards, and changes in consumer attitudes, the number of Chinese people traveling to coastal cities for vacations is growing. In 2017, the number of tourists and the total income from tourism in Sanya reached 18.3097 million and $\$ 58.20$ billion, which are 3.03 and 4.46 times the 2008 figures, respectively. However, the rapid development of the tourism industry has exacerbated environmental pollution and ecological damage, and the interaction between earnings and the environment is a key factor for achieving regional sustainability. To achieve the coordinated development of the tourism industry and ecological environment, local governments should progressively change the status quo of industrial development, which solely relies on tourism, and innovate the development model of industry. Simultaneously, local governments should promote ecological restoration projects, centralized pollution control, comprehensive environmental treatment projects, and ecological restoration projects in coastal cities. In addition, local governments should improve waste treatment technologies and methods, and promote healthy low-carbon tourism through increasing environmental investment and remediation efforts. Doing so would reduce the impact of tourism on coastal environments and provide a favorable ecological environment for developing tourism in coastal cities.

\section{Conclusion}

The ultimate goal of sustainable tourism management is to meet the requirements of tourism development and environmental protection, especially in coastal resort cities where the ecological environment is fragile and tourism is developing rapidly. The negative impact of tourism on the environment has been widely discussed; however, appropriate indices and methods are required to accurately describe the sensitive relationship between the tourism and environmental systems. The CCDM provides an effective approach for evaluating the impact of tourism on the regional environment. The complexity and systematic features of the CCDM make it a vital instrument for clarifying the coordination, interaction, and feedback effects among various factors. Moreover, the weight of the evaluation index-determined through IEW - can effectively avoid subjectivity in the calculations. We combined the CCDM and IEW, and found this method to be feasible for determining which economic efficiency and environmental protection subsystems contribute the most to the tourism-environment coupling model. In the future, we should select appropriate indices, obtain detailed data, and construct a complete evaluation system to analyze the coordination level of the tourism industry and ecological environment more accurately and comprehensively. 


\section{Acknowledgments}

This research was supported by the National Natural Science Foundation of China (Grant No. 41971189) and the Youth Fund of Humanities and Social Sciences Program of the Ministry of Education (Grant No. 19YJCZH027).

\section{References}

1 S. Zhang, Y. Wang, and T. Chang: Sens. Mater. 30 (2018) 565.

2 Ch. Y. Lu, W. L. Li, M. Pang, B. Xue, and H. Miao: Sustainability 10 (2018) 711.

3 J . E. Mbaiwa: J. Arid. Environ. 54 (2003) 447.

4 G. Dubois, P. Peeters, J. Ceron, and S. Gössling: Transport Res. A-Pol. 45 (2011) 1031.

5 S. Gössling: Environ. Dev. Sustainability 5 (2003) 383.

6 A. P. Anisimov and A. Y. Ryzhenkov: Environ. Policy Law 43 (2013) 333.

7 A. Holden: Tourism Recreation Res. 38 (2013) 7.

8 D. Lacitignola, I. Petrosillo, M. Catald, and G. Zurlini: Ecol. Model. 27 (2006) 199.

9 T. M. Patterson,V. Niccolucci, and N. Marchettini: J. Environ. Manage. 86 (2008) 408.

10 W. Wei, I. Alvarez, and S. Martin: Ecol. Model. 251 (2013) 108.

11 S. H. Yang: Sci. Geographica Sinca. 14 (1994) 139 (in Chinese).

12 Ch. B. Liao: Trop. Geogr. 19 (1999) 175 (in Chinese).

13 L. Fu, K. G. Xiong, and Y. Gao: Ecol. Econ. 35 (2019) 125 (in Chinese).

14 Q. S. Hu, X. R. He, and H. Guo: J. Nat. Sci. Hunan Norm. Univ. 41 (2018) 15 (in Chinese). 